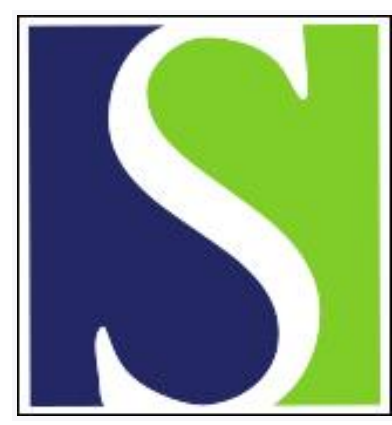

Scand J Work Environ Health 2005;31(4):245-247

https://doi.org/10.5271/sjweh.879

Issue date: Aug 2005

Intervention for return to work-what is really effective?

by Loisel $\mathrm{P}$

Affiliation: Disability Prevention Research and Training Centre, 1111, St Charles Ouest \#101, Longueuil, Québec J4K 5G4, Canada. Patrick.Loisel@USherbrooke.ca

Refers to the following text of the Journal: 2005;31(4):249-257

The following article refers to this text: $2015 ; 41(3): 219-221$

Key terms: editorial; effectiveness; intervention; return to work

This article in PubMed: www.ncbi.nlm.nih.gov/pubmed/16161706

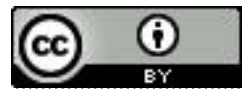




\section{Intervention for return to work—what is really effective?}

Work absenteeism due to musculoskeletal disorders and, more specifically, low-back pain, is a considerable societal and individual problem requiring solutions. The past two decades were fruitful in providing explanations for determining factors leading to work disability. An important step was to come from a pure biomedical perspective to a more comprehensive biopsychosocial model (1). Actually, the causes of disability were shown as being mainly psychosocial and depending on systemic factors of the worker, the workplace, the health care system, and the compensation system (2). Preliminary efforts to identify these causes at the individual worker's level have been attempted (3). In addition, in coherence with this new disability paradigm (2), efforts have been made to develop and evaluate interventions aimed at people returning to work rather than at curing their disease. Moreover, on the basis of the shape of the return-to-work curve (4), the disability process has been divided into three phases (acute, subacute, and chronic) depending on the duration of absence from work (5). The subacute phase has been identified as the "golden hour" to address the disability problem, avoiding unnecessary interventions for most workers that return to work without the need of health care and targeting those at high risk of prolonged disability (5). A first synthesis of the literature on return-towork intervention for subacute back pain was made in 2001, and it retained only two studies (6). Hlobil and his co-workers should be congratulated for quickly replicating such a synthesis, as they found nine relevant studies, indicating the large recent research effort in this field. The conclusions of their study are that return-to-work intervention, when considered as a whole, effectively aids workers to return to work. However, even a summary analysis of the reviewed interventions shows a considerable discrepancy between the content of the interventions. This content is distributed in a variable way through the different analyzed studies and may include physical exercise, education, behavioral treatment, ergonomic measures, and case management. Each of type of intervention can be applied in very different ways (eg, education on what?, exercise of what kind?). Moreover, the duration of the interventions varies considerably, from less than 5 hours to full-time during several weeks. In most studies, no clear rationale for choosing a type of intervention or a mix of different types of intervention is given. Due to this intervention discrepancy, such a review may confuse a clinician or a disability manager wanting to apply the "best evidence" in his or her own setting. For example, if a clinician wants to apply "strong evidence", he or she may only read studies that are considered high in quality. However, as the interventions analyzed in these studies differ completely, he or she will hardly be able to make a reasonable choice.

However, guidelines exist, most of them explaining that the main important topics to address in order to facilitate return to work are reassurance of the worker as to his or her condition, links between care providers and the workplace, and bringing the stakeholders together $(7,8)$. Therefore, it currently appears that we know well, at the population level, what causes the problem, we know quite well what to avoid and what should be addressed by disability management, but we do not really know how to do it, which is the rationale for intervention design. Instead, it seems that existing types of intervention, issued from different fields of practice (cognitive behavioral, ergonomics, physical education, disability management) have been used, although they were not designed specifically for the purpose of return to work on a sound scientific basis. As, from the results of the study of Hlobil and his coworkers, any type of return-to-work intervention seems to work (instead of usual care), one could easily conclude that it resembles a Hawthorne effect (9). In the Hawthorne experiments, manipulating 
various work conditions (eg, pay, light levels, restbreaks, etc), including a return to the original conditions, resulted on the average over time in an increase in productivity, which was the announced aim of the intervention. Does making any intervention with the announced aim of facilitating return to work really facilitate return to work?

Another, less disheartening explanation may be that all these effective interventions share some commonly hidden effective components, in the same way that eating walnuts or eating tuna may both be beneficial in the prevention of heart disease because both walnuts and tuna contain the hidden efficacious omega 3 component. It may be that some forms of intervention have found a different way of appropriately reassuring the worker $(10,11)$. Others may have been successful in making an appropriate link with the workplace [ie, a cognitive behavioral intervention made inside the workplace $(12,13)$, as well as an ergonomic intervention (14)]. Conversely, a cognitive behavioral intervention without a link to the workplace was found to be ineffective (15). Two very recent studies that have appeared after the data collection of Hlobil and his co-workers confirm that a cognitive behavioral intervention in a clinical setting without any link to the workplace has delayed return to work (16) and that an ergonomic intervention was effective with respect to return to work (17). A currently unknown "workplace effect" may be hidden inside an intervention or present in the context in which it is delivered. As proposed by Hlobil and his colleagues, future research should focus on opening the black box on return-to-work interventions in order to understand which components can shorten work absenteeism.

Finally, we learned from Hlobil and his colleagues that a certain range of complex interventions are better than the so-called "usual care". Future randomized controlled trials should stop comparing interventions to usual care, as it may even appear unethical not to offer patients something that is clearly known to be ineffective. The research effort should be dedicated to sound intervention development, targeted towards a specific aim shown as useful for aiding return to work (eg, reassurance) and based on a specific rationale (eg, a method known to provide effective reassurance). This approach would allow the testing, through the use of randomized controlled trials, of a well-designed specific intervention against another well-designed specific intervention, and would also allow the isolation of the few final effective components that will make interventions simpler, more effective, and more cost-effective. The same kind of methodological effort that has been made for years in questionnaire design to ensure content and construct validity should be applied to intervention design. Efforts and costs of randomized controlled trials will then be applied to assess the empirical effectiveness and cost-effectiveness of interventions designed on a valid foundation.

\section{References}

1. Waddell G. Biopsychosocial analysis of low back pain. Baillieres Clin Rheumatol 1992;6:523-57.

2. Loisel P, Durand MJ, Berthelette D, Vézina N, Baril R, Gagnon D, et al. Disability prevention—new paradigm for the management of occupational back pain. Dis Manage Health Outcomes 2001;9:351-60.

3. Durand MJ, Loisel P, Hong QN, Charpentier N. Helping clinicians in work disability prevention: the work disability diagnosis interview. J Occup Rehabil 2002;12:191-204.

4. Spitzer WO, LeBlanc FE, Dupuis M. Scientific approach to the assessment and management of activity-related spinal disorders: a monograph for clinicians: report of the Quebec Task Force on Spinal Disorders. Spine 1987; 12:S1-59.

5. Frank J, Sinclair S, Hogg-Johnson S, Shannon H, Bombardier C, Beaton D, et al. Preventing disability from work-related low-back pain-new evidence gives new hope-if we can just get all the players onside. CMAJ 1998;158:1625-31.

6. Karjalainen K, Malmivaara A, Van Tulder M, Roine R, Jauhiainen M, Hurri H, et al. Multidisciplinary biopsychosocial rehabilitation for subacute low back pain in working-age adults. Spine 2001;26:262-9.

7. Fordyce WE. Back pain in the workplace: management of disability in non specific conditions. Seattle (WA): IASP Press; 1995.

8. Bigos S, Bowyer O, Braen G. Acute low back problems in adults: Clinical Practice Guideline no 14. Rockville (MD): Agency for Health Care Policy and Research (AHCPR), Public Health Service, US Department of Health 
and Human Services; 1994. AHCPR publication no 95-0642.

9. Mayo E. The human problems of an industrial civilization. New York (NY): MacMillan; 1933.

10. Indahl A, Velund L, Reikeraas O. Good prognosis for low back pain when left untampered—a randomized clinical trial. Spine 1995;20:473-7.

11. Hagen EM, Eriksen HR, Ursin H. Does early intervention with a light mobilization program reduce long-term sick leave for low back pain? Spine 2000;25:1973-6.

12. Lindström I, Öhlund C, Eek C, Wallin L, Peterson L, Fordyce WE, et al. The effect of graded activity on patients with subacute low back pain: a randomized prospective clinical study with an operant-conditioning behavioral approach . . . including commentary by Nelson RM with author response. Phys Ther 1992;72:279-93.

13. Staal JB, Hlobil H, Twisk JW, Smid T, Koke AJ, van Mechelen W. Graded activity for low back pain in occupational health care: a randomized, controlled trial. Ann Intern Med 2004;140:77-84.

14. Loisel P, Abenhaim L, Durand P, Esdaile JM, Suissa S, Gosselin L, et al. A population-based, randomized clinical trial on back pain management. Spine 1997;22:2911-8.

15. Storheim K, Brox JI, Holm I, Koller AK, Bo K. Intensive group training versus cognitive intervention in subacute low back pain: short-term results of a single-blind randomized controlled trial. J Rehabil Med 2003;35:13240.

16. Steenstra I. Back pain management in Dutch occupational health care [dissertation]. Amsterdam: Vrije University; 2004.

17. Anema JR. Low back pain, workplace intervention and return-to-work [dissertation]. Amsterdam: Vrije University; 2004.

Patrick Loisel, MD

Disability Prevention Research and Training Centre

1111, St Charles Ouest \#101

Longueuil, Québec

J4K 5 G4

Canada

[E-mail: Patrick.Loisel@USherbrooke.ca] 
